\title{
O estado pastor e os incentivos tributários no setor automotivo
}

\author{
The 'busbandry' state and the tax incentives \\ in the automobile sector
}

MARIO G. SCHAPIRO*

\begin{abstract}
RESUMO: Este trabalho tem o objetivo de descrever os incentivos tributários que foram implementados nas últimas décadas com vistas a promover a competitividade do setor automotivo. Além disso, pretende qualificar o papel que o Estado tem desempenhado neste segmento. Baseado na literatura de regulação econômica e de economia política, o trabalho sugere que as políticas tributárias adotadas para o setor têm conformado mais um Estado "pastor" que um Estado "parteiro". Isto é, os incentivos tributários têm se orientado para corrigir falhas sistêmicas e assim proteger um segmento já estabelecido e não propriamente para estimular a formação de novas competências econômicas.

PALAVRAS-CHAVE: Incentivos tributários; setor automotivo; Estado; regulação; desenvolvimento econômico; política industrial; OMC.
\end{abstract}

ABSTRACT: Taking into account longevity of tax incentives in the automobile sector, this paper intends to pursue two consecutive objectives. Firstly, the paper describes the incentives implemented in the last decades were designed to promote the sector's competitiveness. Secondly, this article presents a qualitative assessment of the role developed by the State in this segment. Based on literature on political economy and regulation, the claim of this research is that tax policies adopted in favor of automobile sector have favored more a "husbandry" State, rather than a "midwifery" one. In other words, the public policies established were typically oriented to protect a previous defined segment, instead of stimulating new competences and capabilities.

KEYWORDS: Tax incentives; automobile sector; state; regulation; economic development; industrial policy; WTO.

JEL Classification: K23; K34; L52; L62; O25; P16.

* É professor em regime de tempo integral na FGV Direito SP. Email: mario.schapiro@fgv.br. Submetido:10/Setembro/2015; Aprovado: 19/Maio/2016. 


\section{INTRODUÇÃO}

Com o desarranjo do ensaio novo-desenvolvimentista, a economia brasileira tem se orientado pela proposição de um agudo ajuste fiscal. O sentido da nova agenda é o da contenção das despesas e dos subsídios públicos. Há, no entanto, exceções a esta nova regra geral e uma delas é o setor automotivo, que não só segue titular dos benefícios de um regime especial de tributação - o Inovar-Auto -, como também foi objeto de novas propostas de estímulo. ${ }^{1} \mathrm{~A}$ assimetria entre o setor automotivo e os demais não é propriamente uma novidade no funcionamento real da ordem econômica brasileira. Essa tem sido uma constante regulatória nas últimas décadas.

No início dos anos 1990, quando a orientação do governo era buscar competitividade e aumentar a concorrência, foi estabelecida uma câmara setorial tripartite, entre governo, empresários e empregados, para assim promover medidas de proteção ao setor automotivo. Anos mais tarde, quando da implementação do Plano Real, o Governo Federal deu causa a uma ampla reforma regulatória, ancorada na rejeição de políticas industriais setoriais. Não obstante a tônica liberal da época, o setor automotivo foi novamente favorecido, desta vez com um regime especial de tributação - Novo Regime Automotivo. Em 2004, quando a política industrial foi restabelecida como agenda de governo, o alvo de suas medidas voltava-se para a promoção da inovação em segmentos tidos como portadores de futuro. Os anos se passaram e a lógica anterior se repetiu: um novo regime especial de tributação para o setor automotivo foi incluído nas novas versões da política industrial.

Reconhecendo a permanente adoção de incentivos tributários para o setor automotivo, este trabalho tem dois objetivos consecutivos. O primeiro deles é descrever os incentivos que foram implementados nas últimas décadas com vistas a promover a competitividade do setor, permitindo assim uma visão de conjunto sobre o marco normativo e a dinâmica econômica do setor. O segundo objetivo é qualificar o papel que o Estado tem desempenhado neste segmento.

Nessa linha, o argumento do trabalho é o de que as políticas tributárias adotadas para o setor automotivo têm conformado um Estado "pastor" e não propriamente um Estado "parteiro". ${ }^{2}$ Isto é, as políticas públicas estabelecidas por meio de incentivos tributários têm se orientado mais para proteger um segmento já estabelecido, do que para estimular a formação de um novo setor ou de novas competências econômicas.

Três fatores parecem estar associados a este perfil de intervenção. O primeiro são as restrições impostas pelas OMC, que reduzem os espaços para a adoção de

\footnotetext{
${ }^{1}$ O Governo Federal estabeleceu um grupo de trabalho interministerial com o setor automotivo e o Banco do Brasil firmou um protocolo de intenções com a Anfavea, para ampliar o crédito para o segmento. Ver: <http://www.brasil.gov.br/economia-e-emprego/2015/04/grupo-interministerial-iradiscutir-medidas-de-estimulo-ao-setor-automotivo/grupo-interministerial-ira-discutir-medidas-deestimulo-ao-setor-automotivo/view>, acesso em 02/09/2015.
}

${ }^{2} \mathrm{O}$ conceito é de Peter Evans. Cf. Evans, 1995. 
regulações industriais com maior potencial transformador. O segundo é o instrumento adotado, incentivos tributários, que é mais adequado para sustentar soluções incrementais e de curto fôlego. O terceiro é a economia política da política industrial, que tem favorecido ações de menor envergadura, voltadas a aliviar problemas conjunturais da competitividade setorial.

O trabalho está organizado em outras quatro seções. A próxima, apresenta uma sucinta revisão da literatura com a finalidade de estabelecer um marco analítico para avaliar o papel do Estado no setor automotivo. A seção seguinte descreve três políticas de incentivo tributário adotadas em benefício deste segmento: as medidas resultantes das Câmaras Setoriais, de 1991 e 1994, o Novo Regime Automotivo, de 1995 a 1999, e o Inovar-Auto, de 2012. A quarta seção procura fazer a análise qualitativa, apresentando o Estado como um pastor do setor automotivo. A última traz as conclusões.

\section{ESTADO, REGULAÇÃO E DESENVOLVIMENTO}

Ultrapassando a dicotomia entre falhas de mercado e falhas de governo, que marcou os termos do debate da economia política no segundo pós-guerra, a literatura sobre desenvolvimento, notadamente Evans (1995), Wade (2003), Amsden (1999), Kohli (2004) e Rodrik (2007), tem convergido para reconhecer que, sob determinadas condições, o Estado cumpre um papel relevante na promoção das estratégias de crescimento. Nos termos de Rodrik (2009): "industrial policy: don't ask why, ask how". Nesses termos, a questão que se coloca para os analistas é menos de questionar se o Estado deve ou não desempenhar um papel relevante na economia e mais o de avaliar suas condições institucionais e os instrumentos empregados para impulsionar os mercados.

Este trabalho volta-se a analisar um destes instrumentos: os incentivos tributários estabelecidos em benefício do setor automotivo brasileiro. Nos termos da literatura, os incentivos tributários, tanto quanto as regras de limitação da propriedade ou as imposições de condicionalidade sobre as condutas econômicas, são como mecanismos regulatórios, ou seja, instrumentalizam uma atuação estatal voltada a alterar o status quo econômico. ${ }^{3}$ A diferença entre a regulação promovida pelos incentivos e aquela afeita aos comandos e controles é o tipo de sanção empregada para conformar os comportamentos dos agentes econômicos. No caso dos incentivos, ao invés da imposição de uma restrição e de uma penalidade, as regras estabelecem uma sanção premial, ou seja, uma consequência regulatória positiva, que procura induzir as decisões alocativas privadas. ${ }^{4}$

O teor da alteração no status quo econômico depende, por sua vez, da racionalidade de economia política que modula a atuação regulatória constitutiva da

\footnotetext{
${ }^{3}$ Schapiro, 2012, p. 13.

${ }^{4}$ Ver Ogus, 2004, pp. 1-2; Webb, 1993, p. 10; Bobbio, 1977.
} 
política industrial. ${ }^{5}$ De um lado, figuram as atuações corretivas, que são aquelas circunscritas a correção de falhas sistêmicas no ambiente de negócios. Nos termos de Cimoli et al., ${ }^{6}$ o papel da regulação nesse caso é o de desobstruir o funcionamento dos mercados, mitigando as suas falhas e preservando assim suas atuais vantagens comparativas. Empregando-se uma tipologia já consolidada e utilizada por Peter Evans, ${ }^{7}$ esse tipo de ação regulatória conformaria um Estado pastor, isto é, um Estado que protege, corrige, gerencia os ativos existentes, mas não provê novas competências ou novos setores.

De outro lado, situam-se as atuações regulatórias transformadoras, que são aquelas orientadas para uma transformação das vantagens comparativas correntes. Para isso, procuram não apenas corrigir falhas institucionais ou sistêmicas dos mercados, mas principalmente instituir e conformar um novo padrão competitivo, capaz de impulsionar novas vantagens comparativas. Utilizando a mesma referência de Evans, essa ação regulatória transformadora pressupõe uma intervenção de um Estado parteiro, isto é, de um Estado encarregado de estimular inovações e a promover novos setores ou novas competências econômicas nos setores existentes.

Com base nesses insumos, as próximas seções procurarão respectivamente descrever e avaliar o tipo de ação regulatória que os incentivos tributários têm representado no setor automobilístico. Serão analisadas três experiências transcorridas nas últimas décadas: (i) os incentivos decorrentes da Câmara Setorial Automotiva implementada entre 1991 e 1992; (ii) o Novo Regime Automotivo, estabelecido entre 1995 e 1999, e (iii) o Inovar-Auto, instituído em 2012.

\section{CÂMARAS SETORIAIS, NOVO REGIME AUTOMOTIVO E INOVAR-AUTO: TRÊS EXPERIÊNCIAS DE INDUÇÃO DO SETOR AUTOMOTIVO}

A partir dos anos 1990, apesar da desarticulação do arranjo desenvolvimentista, o segmento automotivo passou a contar recorrentemente com medidas fiscais e tarifárias, que assumiram desde então um lugar central em sua dinâmica competitiva. Para além de medidas pontuais, como as reduções de IPI sobre automóveis, adotadas no contexto das crises internacionais, como as de 1997 e de 2008, foram implementados desde 1990 pelo menos três regimes tributários especiais para o segmento: o regime tributário decorrente dos acordos da Câmara Setorial, entre 1991 e 1994, o Novo Regime Automotivo, estabelecido entre 1995 e 1999 e, recentemente, o Inovar-Auto, firmado em 2012.

$\mathrm{Na}$ realidade, o setor automotivo brasileiro tem sido um cliente permanente das políticas públicas de incentivo. No período desenvolvimentista, entre os anos 1950 e 1980, as tarifas de importação garantiram uma seletividade estratégica

\footnotetext{
${ }^{5}$ Sobre os tipos de racionalidade indutora, ver Schapiro, 2012, pp. 11-16.

${ }^{6}$ Cimoli et al., 2009, p. 20.

${ }^{7}$ Sobre as funções do Estado no desenvolvimento e, em particular, para as funções pastor e parteiro, ver Evans, 1995.
} 
para o segmento, combinando proteção de mercado para os veículos manufaturados nacionalmente, com facilidades para a importação de seus insumos industriais. No campo da regulação cambial, regras como a instrução normativa 113, da Superintendência da Moeda e do Crédito - SUMOC, autorizava as montadoras a importar os bens de capital necessários para a montagem dos automóveis, sem que precisassem contar com cobertura cambial, o que à época constituía uma excepcionalidade. Finalmente, as empresas estatais, encarregadas da produção local de insumos garantiram um fornecimento a baixo custo e os bancos públicos atuaram como provedores financeiros, ofertando recursos a taxas subsidiadas para as empresas do complexo automotivo. ${ }^{8} \mathrm{O}$ resultado deste conjunto foi relativamente bem-sucedido: entre os anos 1950 e os anos 1980, o setor tornou-se um dos mais relevantes, chegando a representar $15,6 \%$ do PIB industrial, em $1975 .{ }^{9}$

Nos estertores do desenvolvimentismo, no entanto, o setor automotivo passou a acusar sintomas de crise, como a perda de competitividade e a defasagem tecnológica. ${ }^{10} \mathrm{O}$ mercado brasileiro de automóveis ficara à margem da dinâmica competitiva global, registrando um atraso tecnológico em termos de automação, de capacidade de inovação e de competitividade. ${ }^{11}$ É revelador que, depois de ter representado $15,6 \%$ do PIB industrial, em 1975, o setor automotivo passou ao patamar de apenas $10,6 \%$ do PIB industrial, em $1991 .^{12}$

Dados da Anfavea, analisados por Arbix, ${ }^{13}$ indicam que a produção de veículos iniciava os anos 1990 já em patamar de esgotamento. Em 1992, o segmento produziu um volume de autoveículos (1.073.761) inferior ao que havia produzido em 1980 (1.165.174). Além disso, enquanto nos anos 1980 (entre 1980 e 1989), a média anual de venda de automóveis produzidos nacionalmente foi em torno de 575 mil unidades, em 1990 foram vendidos cerca de 533 mil veículos, número que chega a 583 mil em 1991, e que recua para 577 mil, em $1992 .{ }^{14}$ Naturalmente, esse cenário impactava diretamente o ambiente trabalhista que, entre 1990 e 1991, registrou uma queda de $14 \%$ no volume de empregos no segmento metalúrgico do $\mathrm{ABC}$, que à época era o principal reduto das montadoras..$^{15}$

A reação a esta situação de crise não demorou a ocorrer e foi processada com a adoção de medidas tributárias resultantes dos dois acordos automotivos celebrados no âmbito de uma câmara setorial tripartite que reuniu governo, trabalhadores e empresários. Os resultados positivos foram colhidos na forma de um alívio conjuntural nas pressões competitivas do setor. Anos depois, entretanto, o segmento

\footnotetext{
${ }^{8}$ Comin, 1998, pp. 21-28.

${ }^{9}$ Arbix, 1996, p. 39.

${ }^{10}$ Arbix, 1996, pp. 35-57.

${ }^{11}$ Arbix, 1996, pp. 35-57.

${ }^{12}$ Anfavea, 2014, p. 42.

${ }^{13}$ Arbix, 1996, p. 38.

${ }^{14}$ Comin, 1998, p. 120.

${ }^{15}$ Arbix, 1996, p. 68.
} 
voltaria a vivenciar uma nova crise de competitividade e os remédios tributários tornariam a ser articulados, dando origem assim a um ciclo permanente, uma ciranda conhecida e repetitiva: crise setorial - pressão política - indução tributária.

\section{AS CÂMARAS SETORIAIS E OS INCENTIVOS TRIBUTÁRIOS DE 1992 A 1994}

A câmara setorial automotiva iniciou seus trabalhos no final de 1991, organizada por meio de grupos de trabalho compostos por representantes dos trabalhadores, empresários e governo. Seguindo uma lógica de gestão corporativa, todos os grupos envolvidos cederam parcela de seus interesses, com vistas a proporcionar um acordo que maximizasse o resultado global. Inicialmente previsto para vigorar por 90 dias, o acordo foi estendido até 31 de dezembro de 1992. O principal acordo era o de uma redução de $22 \%$ do preço dos automóveis, o que seria obtido por uma partilha tripartite de responsabilidades. ${ }^{16}$

Ao Governo coube as seguintes medidas: (i) redução de $12 \%$ na carga tributária (sendo 6\% de IPI e a sugestão ao Confaz para redução de 6\% de ICMS); (ii) a edição de nova regulação, pelo Banco Central, que permitisse a reabertura dos consórcios; (iii) a definição de um programa de financiamento para automóveis e caminhões por meio dos bancos públicos, e (iv) a definição de um projeto de lei com incentivos para exportação. Os empresários assumiram o compromisso de reduzir a sua margem de lucro, sendo que $4,5 \%$ da redução seria devido às montadoras e $3 \%$, aos fornecedores de autopeças. Além disso, o setor empresarial comprometeu-se com uma política de correção dos salários e de manutenção do nível de emprego até junho de 1992 (prazo posteriormente estendido até julho de 1993). Os empregados, por sua vez, aceitaram os termos da política salarial e prorrogaram a data-base da categoria, que inicialmente seria em $1^{\circ}$ de abril, para $1^{\circ}$ de julho.

No ano seguinte, já no governo Itamar Franco, em fevereiro de 1993, foi firmado o segundo acordo da Câmara Automotiva. Em relação ao primeiro acordo, a segunda versão teve como marca diferencial o estabelecimento de metas, para além da redução do preço dos veículos. Assim, complementarmente ao compromisso de baixar os preços em adicionais $10 \%$, foram estipuladas metas de vendas de veículos e de investimentos. Com relação às vendas, o objetivo acordado foi o de atingir o montante de 1,2 milhão de unidades em 1993, 1,35 milhão em 1994, 1,5 milhão em 1995, e 2 milhões em 2000. Já com relação aos investimentos, os empresários se comprometeram a um aporte de global de US\$ 20 bilhões, até o ano 2000, a serem alocados na ampliação da capacidade produtiva e na modernização da produção.

$\mathrm{Na}$ mesma linha do primeiro acordo, a viabilização dos objetivos contou com a partilha dos encargos. Entre outras medidas adotadas, tais como aumento do prazo dos consórcios e a ampliação dos financiamentos via BNDES, o Governo Federal assumiu um novo desconto de IPI, na faixa de $6 \%$ para automóveis e de $2 \%$ para veículos comerciais leves, e comprometeu-se ainda a propor ao Confaz as

${ }^{16}$ Arbix, 1996, pp. 119-146; Comin, 1998, pp. 41-50; Anderson, 1999, pp. 17-22. 
seguintes reduções de ICMS: de $12 \%$ para $9 \%$ para veículos com menos de mil cilindradas; de $12 \%$ para $7 \%$ para os caminhões; e de 8,8 para $7 \%$ para os tratores e máquinas agrícolas. Os empresários, encarregados de promover os investimentos, assumiram o compromisso de realizar novas reduções nas margens de lucro e os trabalhadores acataram a política salarial, baseada em um escalonamento dos aumentos reais de salário, que seria diferido entre os anos de 1993, 1994 e 1995. ${ }^{17}$ A tabela a seguir sintetiza as principais mudanças tributárias conduzidas pelos acordos do setor e indica o impacto gerado nos preços finais dos veículos.

Tabela 1: Alíquotas e Participação dos Tributos no Preço dos Automóveis (\%)

\begin{tabular}{|c|l|c|c|c|c|}
\hline \multirow{2}{*}{ Ano } & \multicolumn{1}{|c|}{ Tributos } & $\begin{array}{c}\text { Automóveis } \\
\text { Até } 1000 \mathrm{cc}\end{array}$ & $\begin{array}{c}\text { Automóveis } \\
\text { Até 100 hp }\end{array}$ & $\begin{array}{c}\text { Automóveis } \\
\text { Mais 100 hp }\end{array}$ & $\begin{array}{c}\text { Comerciais } \\
\text { Leves }\end{array}$ \\
\hline 1990 & IPI & 20 & 37 & 42 & 16 \\
\hline \multirow{5}{*}{} & ICMS & 18 & 18 & 18 & 18 \\
\cline { 2 - 6 } & PIS & 0,65 & 0,65 & 0,65 & 0,65 \\
\cline { 2 - 6 } & Finsocial & 1,2 & 1,2 & 1,2 & 1,2 \\
\cline { 2 - 6 } & Participação no preço & 34,5 & 42,2 & 44,1 & 32,2 \\
\hline \multirow{5}{*}{1991} & IPI & 20 & 37 & 42 & 16 \\
\hline \multirow{3}{*}{1992} & ICMS & 18 & 18 & 18 & 18 \\
\cline { 2 - 6 } & PIS & 0,65 & 0,65 & 0,65 & 0,65 \\
\cline { 2 - 6 } & Finsocial & 2 & 2 & 2 & 2 \\
\cline { 2 - 6 } & Participação no preço & 35,6 & 43,1 & 45 & 33,4 \\
\hline \multirow{3}{*}{} & IPI & 14 & 31 & 36 & 10 \\
\hline & ICMS & 12 & 12 & 12 & 12 \\
\cline { 2 - 6 } & PIS & 0,65 & 0,65 & 0,65 & 0,65 \\
\cline { 2 - 6 } & Finsocial & 2 & 2 & 2 & 2 \\
\cline { 2 - 6 } & Participação no preço & 27,1 & 36,1 & 38,4 & 24,4 \\
\hline
\end{tabular}

Fonte: Anfavea.

Entre os analistas da Câmara Setorial, Arbix ${ }^{18}, \operatorname{Comin}^{19}$ e Anderson ${ }^{20}$ apresentam uma avaliação positiva de seu funcionamento. Dados da Receita Federal apresentados por Anderson ${ }^{21}$ indicam que, entre 1990 e 1993, a arrecadação de IPI, na cadeia automotiva (incluindo aço, automóveis, peças e acessórios), sofreu um acrés-

${ }^{17}$ Para a descrição destas medidas, ver Arbix, 1996, pp. 119-146; Comin, 1998, pp. 41-50; Anderson, 1999, pp. 17-22.

${ }^{18}$ Arbix, 1996, pp. 119-146.

${ }^{19}$ Comin, 1998, pp. 41-50.

${ }^{20}$ Anderson, 1999, pp. 17-22.

${ }^{21}$ Receita Federal apud Anderson, 1999, p. 27. 
cimo substantivo, passando de um patamar de R \$ 1.187.701, em 1990, para R\$ 1.464.127, em 1993.22 A avaliação dissonante é de Lucia Helena Salgado, ${ }^{23}$ para quem o acordo automotivo implicou renúncia de receita, uma vez que a arrecadação tributária poderia ter sido superior se não tivessem sido celebrados os compromissos de redução de IPI e de ICMS.

Quanto ao nível de emprego, Arbix ${ }^{24}$ assinala que os acordos não foram capazes de criar novos postos de trabalho, constatando-se inclusive uma redução do nível de emprego, quando comparado ao cenário de 1990. Mesmo assim, as avaliações de $\operatorname{Arbix}^{25}$ e também de Anderson ${ }^{26}$ são positivas porque os acordos teriam interrompido uma tendência acentuada de desemprego no setor. Já as metas de venda, por sua vez, foram alcançadas. Enquanto a meta inicial, em 1993, era de 1,2 milhão de unidades vendidas, o segmento vendeu 1.391.435; o mesmo ocorreu em 1994, com a venda de 1.581.389 unidades e, em 1995, com 1.629.008 unidades.

Os resultados apresentados pela câmara setorial foram assim parcialmente favoráveis. Todavia, o saldo positivo perduraria por apenas alguns anos. Já em 1995, novas pressões competitivas levariam o Governo Federal a adotar um novo plano de apoio para o setor: tratava-se do Novo Regime Automotivo. Desta vez, contudo, a margem de manobra do Governo seria menor, seja em razão dos controles exercidos pela Organização Mundial do Comércio - OMC, seja pela representação dos interesses no Congresso Nacional.

\section{A NÃO POLÍTICA INDUSTRIAL DOS ANOS 1990 \\ E O NOVO REGIME AUTOMOTIVO DE 1995 A 1999}

Logo após a celebração do segundo acordo, em 1993, a câmara setorial foi paulatinamente desarticulada como locus decisório, sendo definitivamente encerrada com a vigência da governança econômica do Plano Real. A partir de então, o Governo Federal centralizou as decisões econômicas no Ministério da Fazenda e deixou de recorrer às câmaras para a tomada de decisões referentes às questões tributárias e salariais.

Neste período houve uma retração da política industrial, inclusive para o setor automotivo. Entre 1994 e 1995, todos os setores e o automotivo, em particular, foram regidos pelos impulsos de mercado, sendo este último especialmente afetado por uma intensa redução das tarifas alfandegárias. No entanto, em um curto espaço de tempo, e contrariando a lógica geral do período, segundo a qual "a melhor

\footnotetext{
${ }^{22}$ Valores de agosto de 1994.

${ }^{23}$ Salgado, 1993.

${ }^{24}$ Arbix, 1996, pp. 119-146.

${ }^{25}$ Arbix, 1996, pp. 119-146.

${ }^{26}$ Anderson, 1999, pp. 30-33.
} 
política industrial é não ter política industrial”27, o Governo Federal voltou a apresentar um conjunto de medidas tributárias para promover o setor automotivo. Tratava-se do NRA - Novo Regime Automotivo, disciplinado originalmente pela Medida Provisória - MP 1024/95, convertida na Lei 9.440/97.

A definição de uma política industrial para o setor automotivo teve o propósito de amenizar efeitos colaterais que desafiavam a gestão macroeconômica. Primeiro, tratava-se de mitigar o desequilíbrio comercial, ocasionado pelo que à época ficou conhecido como "farra das importações". A valorização cambial e a redução das alíquotas de importação, que, por um lado, garantiam maior pressão concorrencial e favoreciam os objetivos do controle inflacionário, por outro, estimulavam em demasia as importações, o que pressionava a balança comercial. Em 1994, quando a alíquota de importações de veículos atingiu o seu menor valor, chegando a $20 \%$, houve um crescimento abrupto, de $179 \%$, na importação de veículos. ${ }^{28}$ Esse panorama se somaria ao de outros segmentos, que igualmente pressionavam as contas externas. No início de 1997, por exemplo, o déficit de conta-corrente chegou a 3,5\% do PIB, ultrapassando, para Comin, ${ }^{29}$ o limiar de segurança, então estabelecido em $3 \%$ do PIB. ${ }^{30}$

Tabela 2: Evolução das Aliquotas de Importação de Veículos

\begin{tabular}{|l|c|l|c|}
\hline \multicolumn{4}{|c|}{ Evolução das Alíquotas de Importação de Veículos } \\
\hline \multicolumn{1}{|c|}{ Período } & Valor (\%) & \multicolumn{1}{|c|}{ Período } & Valor (\%) \\
\hline Março 1990 & 85 & Setembro 1994 & 20 \\
Fevereiro 1991 & 60 & Fevereiro 1995 & 32 \\
Fevereiro 1992 & 50 & Março 1995 & 70 \\
Outubro 1992 & 40 & Janeiro 1997 & 63 \\
\hline Junho 1993 & 35 & & \\
\hline
\end{tabular}

Fonte: IPEA, apud De Negri, 1997.

O segundo problema que desafiava a gestão macroeconômica da época era a pressão concorrencial exercida pela Argentina na indústria automotiva e de autopeças, no âmbito do Mercosul. ${ }^{31}$ Em 1991, a Argentina havia estabelecido seu Regime Automotriz, garantindo incentivos tributários para as empresas instaladas em seu território, favorecendo assim as importações intramarca.

Em razão da constituição do Mercosul, com a ratificação do Tratado de Ouro Preto, em 1996, bem como em função de acordos anteriores celebrados entre Brasil e Argentina, especificamente no segmento automotivo, como o Acordo de Comple-

\footnotetext{
${ }^{27}$ Frase atribuída ao então Ministro da Fazenda Pedro Malan, de acordo com Campanário e Silva, 2004, p. 21.

${ }^{28}$ Comin, 1998, p. 65

${ }^{29}$ Comin, 1998, p. 63.

${ }^{30}$ Dados de Comin, 1998, p. 63.

${ }^{31}$ Calandro, 2000, pp. 123-125.
} 
mentação Econômica, de 1991, a localização das plantas de montadoras e de autopeças passou a seguir uma arbitragem de benefícios, entre ambos os países. ${ }^{32}$ Nesse contexto, a definição de incentivos tributários na Argentina tinha o efeito de estimular mais deslocamentos de empresas para o seu território, o que efetivamente passou a ocorrer. É o que relata a pesquisa de Bedê, ${ }^{33}$ segundo a qual, em 1995, 25 empresas do ramo de autopeças já tinham se deslocado do Brasil para a Argentina e outras 33 empresas tinham planos de também deslocar suas plantas produtivas.

Diante desse cenário duplamente adverso, assinala Calandro, ${ }^{34}$ marcado por uma relação de comércio internacional desfavorável e por uma pressão competitiva exercida pela Argentina sobre o parque produtivo nacional, o Governo Federal concebeu o Novo Regime Automotivo (NRA), vigente entre 1995 e 1999. A sua linha geral era de oferecer a mesma lógica de incentivos oferecidos pelo regime automotriz argentino. Em contrapartida, as empresas que aderissem ao NRA teriam que garantir um índice de nacionalização na produção dos veículos de, pelo menos, $60 \%$, sendo que se considerariam, para efeitos do índice de nacionalização, as peças produzidas no Brasil ou na Argentina. ${ }^{35}$ Além disso, havia também como contrapartida uma vinculação entre os benefícios de importação e as metas de exportação: originalmente, para cada US\$ 1 importado a empresa deveria exportar US\$ 1,5 (aplicável a partir de 1998).

Diferentemente do ocorrido nos acordos resultantes da câmara automotiva, cujas medidas decorriam de intensa negociação prévia, mas de baixa contestação posterior, a definição do Novo Regime Automotivo, inicialmente centralizada pelas autoridades de governo, teve como peculiaridade a incidência de dois mecanismos de controle que impactaram a sua implementação: um controle liberal exercido pela Organização Mundial do Comércio e um controle democrático exercido pelo Congresso Nacional. Em outros termos, a margem de manobra ficara mais estreita, o que também restringiu o impacto das medidas regulatórias.

No âmbito da regulação internacional do comércio, as medidas do NRA foram denunciadas pelo Japão e pelos Estados Unidos na OMC. Ambos os países assinalaram que a política brasileira violava o tratado de livre comércio ao dar tratamento privilegiado para indústrias nacionais ou para produtos de origem local. $\mathrm{O}$ impasse foi resolvido por meio de um acordo entre os países e o governo brasileiro editou os Decretos 1.987/96, $2.307 / 97$ e 2.638/98, flexibilizando os incentivos do NRA para as exportações de montadoras situadas nos Estados Unidos, Japão, Coreia do Sul e União Europeia. ${ }^{36}$ Pelos termos dos acordos, o Brasil estabeleceria uma cota de importação de 50 mil veículos procedentes dessas regiões, que receberiam o mesmo tratamento tributário dispensado pelo NRA - pagamento de alíquota de

\footnotetext{
32 Cf. Bedê, 1996, p. 141; Calandro, 2000, pp. 123-125.

${ }^{33}$ Bedê, 1996, p. 141.

${ }^{34}$ Calandro, 2000, pp. 123-125.

${ }^{35}$ Ver a respeito De Negri, 1999, pp. 215-217; Calandra, 2000, pp. 123-125 e Comin, 1998, pp. 76-79.

${ }^{36}$ Para essa descrição, ver De Negri, 1999, pp. 215-217.
} 
importação de $35 \%$. Os veículos que excedessem esta cota pagariam a tarifa cheia de $70 \%$ de importação. ${ }^{37}$

A estes custos impostos pelo controle liberal, somaram-se também novos custos fiscais impostos pela negociação parlamentar. Na negociação de aprovação da Medida Provisória que estipulava o NRA, o Congresso pactuou com o Governo a definição de incentivos para o desenvolvimento regional, criando no âmbito do NRA o, assim chamado, Regime Especial. De acordo com a MP 1.532/97, o Regime Especial incluía benefícios tributários adicionais para as empresas que optassem por instalar suas plantas nas regiões Norte, Nordeste e Centro-Oeste. ${ }^{38}$

A avaliação das medidas do NRA é controvertida. Por um lado, o regime foi capaz de mitigar provisoriamente o crescimento das importações, alterando assim uma tendência que se firmava desde $1994 .{ }^{39}$ Os dados da Anfavea, apresentados no gráfico a seguir, ilustram essa conclusão: entre 1995 e 1999, o saldo comercial do setor foi positivo. Por outro lado, os benefícios tributários também foram custosos. As restrições da OMC estancaram o alcance das medidas e as negociações parlamentares amplificaram o custo fiscal do programa. ${ }^{40}$ Também é de considerar a sua efetividade no tempo: a evolução dos dados no final da década de 2000 indica que o setor voltaria a enfrentar rapidamente problemas de competitividade.

Gráfico 1: Balança Comercial de Autoveículos (US\$)

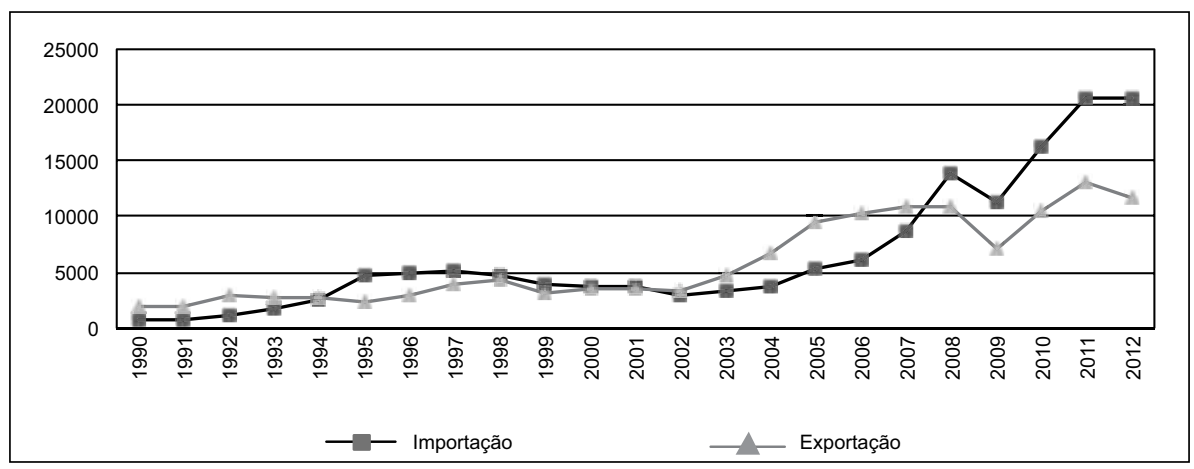

Fonte: Anfavea.

${ }^{37}$ De Negri, 1999 , pp. 215-217.

${ }^{38}$ De acordo com a MP 1.532/97, o Regime Especial incluía benefícios tributários adicionais para as empresas que optassem por se instalar suas plantas nas regiões Norte, Nordeste e Centro-Oeste. Nesses casos, as empresas seriam titulares de uma redução de até $90 \%$ no imposto de importação incidente sobre peças e componentes; de um bônus de $200 \%$ para a importação, obtido com a aquisição de máquinas e equipamentos fabricados no Brasil; além disso, as aquisições de maquinas e equipamentos ficariam isentas de IPI até 1999 e as aquisições de matérias primas e insumos teriam uma redução do IPI em $45 \%$. Finalmente, essas operações teriam ainda isenções de imposto de renda (IR) e também do imposto sobre operações financeiras (IOF) nas operações de câmbio realizadas no pagamento dos bens importados. Ver também De Negri, 1999, p. 217; Calandro, 2000, p. 126; Comin, 1998, pp. 96-97.

${ }^{39}$ De Negri, 1999, pp. 219-223.

${ }^{40}$ Comin, 1998, p. 96. Para uma avaliação custo-benefício do NRA, ver De Negri, 1999. 


\section{O Ativismo Estatal dos Anos 2000 e o Inovar-Auto de 2013 a 2017}

Cerca de dez anos depois do Novo Regime Automotivo, na sequência de uma série de reduções de IPI, implementadas como política anticíclica em razão dos efeitos da crise financeira de 2008, o Governo Federal concebeu mais um regime tributário especial para o segmento automotivo. Trata-se do programa intitulado Inovar-Auto, estabelecido pela Lei 12.715/2012, que resultou da aprovação da Medida Próvisória 563, de 3 de abril de 2012, e pelo Decreto 7.819, de 3 de outubro de 2012.

Assim como ocorrido nas experiências anteriores, também desta vez o setor automotivo enfrentava uma conjuntura econômica adversa, registrando mais uma vez um desequilíbrio na balança comercial. Na realidade, como indica o Gráfico 1, acima, depois de um período positivo que perdurou até 2005, o setor passou a registrar um aumento constante das importações, que finalmente superaram as exportações, em 2008. A rigor, este saldo já se mostrava negativo para alguns mercados desde 2007, como é o caso das transações com Estados Unidos, China e Argentina. ${ }^{41}$ Notadamente, no ano de 2011, quando a nova versão da política industrial - Plano Brasil Maior - foi apresentada, as exportações de veículos atingiram US\$12,9 bilhões, ao passo que as importações alcançaram o montante de US\$ 20,6 bilhões, o que resultou em um saldo negativo de aproximadamente US\$ 7,5 bilhões. ${ }^{42}$

Em termos mais específicos, o Inovar-Auto foi concebido para atender a dois objetivos estratégicos complementares. O primeiro deles era a intenção de atrair novos investimentos para o país, garantindo assim maior nacionalização da produção dos veículos que são adquiridos pelos consumidores brasileiros, o que tenderia a impactar positivamente a indústria de autopeças. O segundo objetivo era o de favorecer um padrão de produção que estivesse nivelado com os patamares internacionais (que já estavam orientados para o incremento da eficiência energética dos motores), e com isso favorecer uma ampliação das exportações. Esses objetivos são apresentados pelo Ministério de Desenvolvimento, Indústria e Comércio, ao listar as finalidades do Inovar-Auto: "investimento em P\&D (inovação); aumento do volume de gastos em engenharia, tecnologia industrial básica (TIB) e capacitação de fornecedores; produção de veículos mais econômicos; aumento da segurança dos veículos produzidos". ${ }^{43}$ Tais finalidades são detalhadas na exposição de motivos que apresenta a proposta de Medida Provisória para a Presidência de República, assinada pelos Ministros responsáveis pela sua confecção. ${ }^{44}$ Assinala o texto:

44. [...] A medida proposta tem por objetivo fortalecer a indústria automotiva nacional e criar incentivos para que haja melhoria do conteúdo

\footnotetext{
${ }^{41}$ Dieese, 2012, pp. 7-17.

42 Anfavea, 2014, p. 48.

43 Brasil, 2013.

${ }^{44}$ A exposição de motivos da MP é assinada pelos Ministros da Fazenda, Desenvolvimento, Indústria e Comércio, Ciência e Tecnologia, Educação, Comunicações, Portos, Saúde, Previdência.
} 
tecnológico dos veículos produzidos no País. A competição mundial nessa indústria se mostra cada dia mais condicionada ao avanço tecnológico e à eficiência produtiva. Vários são os campos onde se esperam avanços nos próximos anos, entre eles a proteção ao meio ambiente, a segurança e a eficiência energética. 45. A experiência internacional de políticas direcionadas à eficiência energética mostra que a introdução de um marco regulatório voltado às emissões veiculares estimulará a capacidade tecnológica das montadoras instaladas no país. A medida promoverá o aumento da eficiência veicular da frota brasileira e permitirá que a indústria automotiva nacional atenda aos atuais padrões de produção da indústria automotiva internacional. Além disso, os níveis atuais de eficiência energética de veículos produzidos no Brasil chegam a ser até $40 \%$ menores que o de veículos semelhantes comercializados na Europa e nos EUA. ${ }^{45}$

A lógica do benefício do Inovar-Auto envolve uma relativa complexidade tributária, que em boa medida se explica pela tentativa de camuflar seus dispositivos de conteúdo local, que poderiam enfrentar restrições por parte da OMC - como de fato ocorreu. O programa estava assentado em uma noção de crédito presumido de IPI. Para se entender a dinâmica deste crédito presumido é preciso ter em conta que um Decreto de 2001, n. ${ }^{\circ} 7.567$, em seu anexo V disciplinava uma versão anterior do regime automotivo. Nesta versão anterior ao Inovar-Auto, a alíquota de IPI havia sofrido um aumento de pelo menos $30 \%$ em relação a base de cálculo vigente na legislação tributária, tanto para veículos nacionais como para importados. Esse Decreto foi revogado pelo Decreto 7.819/2012, que instituiu o Inovar-Auto, mas o seu art. $14, \mathbb{\$} 1^{\circ}$, manteve a previsão de aumento dos $30 \%$ de IPI, tal como assinalava o Decreto anterior.

Nos termos do regime do Inovar-Auto, as empresas devem se habilitar para obter uma redução deste IPI majorado em até $30 \%$. Uma vez habilitadas, as empresas devem realizar investimentos como contrapartida aos benefícios tributários obtidos, sendo que a principal contrapartida é o alcance de níveis preestabelecidos de eficiência energética, garantindo assim uma redução da emissão de poluentes. ${ }^{46}$ A redução do IPI é concedida na forma de créditos que podem ser utilizados em atividades próprias do setor, tais como: aquisição de insumos estratégicos; ferramentaria; despesas com pesquisa, desenvolvimento tecnológico ou capacitação de fornecedores, entre outros (art. 12, Decreto 7.819/2012).

Há, por fim, um incentivo adicional relacionado especificamente a eficiência energética. Para além da regra de eficiência energética mínima, que conjuntamente com as contrapartidas é uma condição de habilitação da empresa para postular a redução de IPI, há a previsão de um desconto adicional deste tributo para empresas que obtiverem uma redução superior nos patamares de emissão de poluentes. Assim, a partir de 2017,

\footnotetext{
${ }^{45}$ Brasil, 2012, p. 6.

${ }^{46}$ Decreto $7.819 / 2012$, arts. $5^{\circ}$ a $8^{\circ}$.
} 
empresas cujos veículos consumissem $15,46 \%$ a menos de combustível seriam beneficiadas com uma redução de $1 \%$ de IPI, e aquelas cujos veículos atingissem uma eficiência energética com consumo 18,84\% menor que a medida de 2013 garantiriam um benefício adicional de $2 \%$ de desconto do imposto. Esses padrões de emissão eram previstos para serem atingidos na União Europeia até o ano de 2015.

De acordo com seu desenho regulatório, os benefícios do Inovar-Auto são extensíveis a empresas estrangeiras que vierem a se instalar no país. Assim como já ocorrera com o Novo Regime Automotivo, nos anos 1990, a confecção do Inovar-Auto resultou da reformulação de um conjunto de incentivos que haviam sido definidos em uma versão anterior do programa e cuja implementação levantava resistências no âmbito da OMC. Tanto é assim que o novo desenho do regime procurou evitar sua caracterização como uma medida protecionista, permitindo a extensão dos benefícios para empresas ainda não instaladas no país. Nos termos deste marco regulador, podem se habilitar a obter os benefícios de IPI as empresas que figurem em uma das seguintes situações: (i) empresas que já produzem no país os veículos automotores que são descritos na Tabela de Incidência do IPI ${ }^{47}$ - TIPI; (ii) as empresas que comercializem tais veículos, ou (iii) as empresas que tenham projeto aprovado para instalação ou ampliação de sua atuação, no Brasil (art. 40, $\$ 2^{\circ}$, Lei $12.715 / 2012$ ).

A bem da verdade, o Inovar-Auto prevê regras de conteúdo local, mas de um modo menos explícito. Ao invés de condicionar os benefícios tributários a uma contrapartida direta de investimentos locais, a regra trazida pelo Decreto 7.819/2012 é algo mais sútil. O art. 12 do Decreto, que trata da apuração dos investimentos que garantem a obtenção dos créditos de IPI, assinala como despesas elegíveis para este fim aquelas realizadas com insumos estratégicos e ferramentaria. O que se considera insumos estratégicos e ferramentaria para fins da regra é regulado por uma portaria ministerial, que estipula uma lista de produtos de origem nacional. O crédito é apurado por meio de um fator multiplicador, que no caso dos automóveis foi estipulado em $1,3 .{ }^{48} \mathrm{Em}$ outros termos, despesas com insumos estratégicos e ferramentaria de procedência nacional podem gerar um crédito de IPI de até $30 \%$, o que indiretamente favorece os objetivos de conteúdo local. ${ }^{49}$

Diante desse panorama, o regime do Inovar-Auto, estabelecido de modo a conciliar os objetivos de induzir competitividade no setor automotivo com as regras do comércio internacional, suscita três questões. A primeira é relacionada ao con-

\footnotetext{
${ }^{47}$ São incluídos neste regime os veículos classificados entre as posições 87.01 a 87.06 da Tabela de Incidência do IPI - TIPI. São eles: veículos automóveis para transporte de dez pessoas ou mais, automóveis de passageiros, caminhões, caminhonetas, furgões e assemelhados e carro-forte para valores. A TIPI e as classificações de produto foram aprovadas pelo Decreto 7.660.

${ }^{48}$ De acordo com o art. $12, \$ 5^{\circ}$, I, do Decreto 7.819/2012, o fator multiplicador será escalonado anualmente, sendo de 1,3, para o primeiro ano de habilitação da empresa; 1,25 , para o segundo ano; 1,15 , para o terceiro ano; 1,10 , para o quarto ano e 1,00 , para o quinto ano.

${ }^{49}$ Diesse, 2012, pp. 43-44.
} 
trole de sua implementação. Estabelecido por um Decreto que recorre a um malabarismo regulatório, para assim procurar coadunar dispositivos de conteúdo local com as restrições existentes a estes expedientes, o regime carece de clareza normativa, o que pode tornar a verificação de sua implementação menos transparente para agentes de controle, sejam eles do Executivo, sejam de outras instâncias de controle. As métricas e contrapartidas não são clarividentes e ainda demandam um trabalho não trivial de certificação e de medição dos investimentos realizados, para fins de garantir uma apuração adequada e assim dar ensejo a obtenção dos créditos tributários.

As demais questões referem-se a sua efetividade. Nesse quesito, uma primeira indagação diz respeito à possibilidade deste regime ficar no meio do caminho, correndo os riscos de uma violação das regras de comércio e, simultaneamente, arcando com mais ônus do que benefícios. Isso porque, se de um lado o regime automotivo prevê implicitamente regras de conteúdo local, de outro, estendeu seus benefícios para empresas não produtoras, que se dedicam a comercialização de veículos. Com isso, há uma chance não desprezível de que o regime automotivo acabe dispendendo recursos fiscais mais para favorecer as importações, realizadas pelas empresas comercializadoras, do que efetivamente as inovações das empresas produtoras. Algo semelhante ocorrera nos anos 1990, com o Novo Regime Automotivo.

Além disso, uma segunda indagação quanto à efetividade do regime diz respeito justamente ao tipo de inovação que foi incentivada. Assumindo que os benefícios tributários sejam capazes de favorecer mais a produção local do que a comercialização, uma questão que se coloca é se o tipo de inovação resultante não é menos radical do que se esperaria para a sustentabilidade da competitividade do setor, a médio prazo. Como assinalam Mesquita, Borges, Santos e Sugano, ${ }^{50}$ a janela de oportunidade para as inovações radicais no setor automotivo são os veículos elétricos ou híbridos, que podem mudar drasticamente o padrão de funcionamento desse mercado. Ao analisar os incentivos do Inovar-Auto, no entanto, os autores salientam que o extrato das medidas, conjugadas com o conjunto da tributação incidente sobre veículos, favorece apenas os veículos tradicionais e não as alternativas híbridas ou elétricas, que são justamente aquelas que mais poderiam promover transformações competitivas no segmento.

A rigor, na ocasião da implementação da primeira versão do Inovar-Auto, os veículos híbridos e elétricos estavam contemplados no Decreto 7.819 (anexo II). Todavia, esses veículos eram classificados na tabela do IPI (estipulada pelo Decreto $7.660 / 2011$ ) com uma alíquota máxima de $55 \%$, e era sobre essa alíquota que incidiam os créditos tributários definidos pelo regime automotivo. Assim, mesmo contemplados pelo programa, a conta geral de sua tributação era desfavorável e por isso o regime automotivo tende a ser mais eficaz nos incentivos a investimentos em veículos tradicionais.

${ }^{50}$ Mesquita, Borges, Santos e Sugano, 2013, pp. 10-11. 


\section{O ESTADO PASTOR NO SETOR AUTOMOTIVO}

A combinação de um ativismo estatal permanente com a sequência de momentos de crise e esgotamento do setor automotivo permite questionar se as medidas indutoras têm sido efetivas para fomentar a consolidação de uma indústria competitiva, capaz de prescindir do apoio público. Nesse sentido, alguns dados do desempenho do setor chamam a atenção, em particular. Primeiro, o nível de emprego parece estar estagnado. A indústria gerava em 2013, em um ano pré-crise, uma quantidade de empregos diretos (153.222) inferior ao montante de 1980 (153.939). ${ }^{51}$ Segundo, não só o volume de exportações enfrenta restrições desde 2006 como, de tempos em tempos, o saldo da balança comercial do setor torna-se negativo, ${ }^{52} \mathrm{o}$ que impacta a gestão macroeconômica.

Além disso, em relação a competitividade e a sustentabilidade futura do setor, é significativo que ainda hoje o segmento enfrente restrições para produzir veículos elétricos ou híbridos no país. Mais representativo ainda é o fato de que, a despeito de tantos incentivos, a carga tributária incidente sobre esses veículos era francamente desfavorável: sem considerar o imposto de importação, a alíquota do IPI era a máxima, 55\%. Não por acaso, em 2012 foram licenciados apenas 115 veículos elétricos e em 2013, 484. ${ }^{53}$

Do ponto de vista das políticas regulatórias, este cenário de impasse parece estar associado a três fatores: as restrições impostas pela OMC; os instrumentos utilizados na indução setorial, e a economia política da política industrial brasileira.

Com relação à OMC, as regras de comércio limitam os espaços da política industrial e assim reduzem a margem de manobra para a adoção de medidas indutoras, que poderiam ter um impacto mais robusto na transformação setorial. ${ }^{54} \mathrm{As}$ limitações experimentadas pelo Novo Regime Automotivo e pelo Inovar-Auto são indicações dessas restrições, que acabam por circunscrever as possibilidades regulatórias. Além disso, há um outro resultado que decorre do manuseio local das regras de comércio: o contorcionismo regulatório, que é adotado pelo governo para camuflar as medidas de estímulos. A consequência disso pode ser o de uma eficácia contida das medidas, além de menor capacidade de controle público de sua implementação e de seus resultados.

A despeito de suas restrições, as limitações transformadoras do setor não podem ser atribuídas apenas às regras de comércio. A capacidade doméstica dos formuladores de política e o ambiente da economia política são também variáveis relevantes. Nesse sentido, é discutível se os incentivos tributários são o mecanismo mais adequado para promover saltos de inovação e de competitividade. Por representar um

\footnotetext{
${ }^{51}$ Anfavea, 2014, p. 46.

52 Anfavea, 2014, p. 48.

${ }^{53}$ Nesses mesmos anos, foram licenciados respectivamente 2.715 .060 e 2.656.971 veículos híbridos. Anfavea, 2014, p. 66.

54 Sobre a redução do espaço para políticas industriais, ver Chang, 2005, pp. 2-6.
} 
alívio de custo e não uma provisão de capital, é um mecanismo que parece ser mais afinado para induzir transformações incrementais e menos dado a favorecer transformações mais substantivas. Em razão dos riscos e incertezas, projetos vocacionados a transformações estruturais demandam políticas mais propicias a tomada de risco empresarial. Este é o caso dos programas públicos de venture capital. Portanto, a escolha do incentivo também está associada ao tipo de resultado colhido.

Finalmente, em uma perspectiva mais ampla, observando-se configuração da economia política, pode-se entender que as medidas regulatórias adotadas no segmento automotivo estão alinhadas com o perfil geral da política industrial brasileira. Muito embora a retomada da política industrial nos últimos anos tenha pretendido promover transformações estruturais no segmento industrial, suas medidas efetivas caracterizaram-se por ações pontuais e muitas vezes erráticas, orientadas para suprir deficiências sistêmicas do ambiente de negócios. ${ }^{55}$ Dada a dificuldade em se realizar reformas institucionais mais abrangentes, como é o caso da reforma tributária, a agenda da política industrial acabou por assumir o encargo de reduzir custos de transação setoriais, para com isso aliviar rudimentarmente as pressões competitivas. ${ }^{56}$ No setor automotivo isso fica bastante evidente, quando se considera que a carga tributária brasileira incidente sobre os automóveis representa cerca de $30 \%$ do preço final do veículo, ${ }^{57}$ algo muito superior à carga de países como Itália e Espanha, cuja tributação responde por cerca de $17 \%$ do preço final. ${ }^{58} \mathrm{O}$ alívio de custos é uma das primeiras demandas a ser equacionada pelos formuladores da política industrial, o que pode explicar a atenção dispensada aos incumbentes e a falta de atenção com os entrantes do futuro, os carros elétricos e híbridos, por exemplo.

Nesse cenário, marcado por dificuldades setoriais e limitações institucionais, cumpre ao Estado um papel reiterado de pastoreio competitivo. A julgar pelos casos examinados, a ação indutora do Estado tem assumido uma feição corretiva de problemas conjunturais apresentados pelo setor, porém menos propensa a fomentar saltos tecnológicos e competitivos. A recorrência das medidas de indução e a repetição dos problemas a demandarem a intervenção pública são evidências que corroboram a inferência interpretativa deste trabalho.

\section{CONSIDERAÇÕES FINAIS}

Uma visão de conjunto do segmento automotivo e dos incentivos fiscais empregados pelas sucessivas políticas industrias direcionadas ao setor indica uma

\footnotetext{
${ }^{55}$ Para uma análise destes impasses na Política de Desenvolvimento Produtivo, ver Almeida, 2008. Para um mapeamento das medidas do Plano Brasil Maior, ver Schapiro, 2012.

${ }^{56}$ Schapiro, 2012.

${ }^{57}$ Anfavea, 2014, p. 54. Esse valor considera um IPI básico e um automóvel a gasolina não popular, isto é, entre 1000 e 2000 cilindradas. O valor do IPI é diferente conforme a potência do motor.

${ }^{58}$ Anfavea, 2014, p. 54.
} 
combinação de crises setoriais periódicas e intervenções voltadas ao curto prazo. De um lado, a indústria alterna seguidos ciclos de acomodação e crise, indicando um problema latente de competitividade que se recoloca periodicamente. De outro lado, em razão de sua expressiva participação na economia nacional, representando em média $15 \%$ do PIB industrial nos últimos vinte anos, o segmento tem sido um cliente permanente de medidas de incentivo, até mesmo nos períodos em que a orientação da política econômica era de maior restrição para as políticas industriais.

Nos termos analíticos empregados neste trabalho, trata-se de uma intervenção regulatória compatível com a de um Estado pastor, mas que não tem sido capaz de impulsionar novas e mais definitivas competências. Este diagnóstico fica ainda mais evidente quando se leva em conta que a fração da indústria com maior propensão a empreender uma inovação radical na eficiência energética, a saber, os veículos híbridos, não tem sido contemplada a contento nos incentivos tributários.

\section{REFERÊNCIAS BIBLIOGRÁFICAS}

ALMEIDA, Mansueto. (2009), “Desafios da Real Política Industrial Brasileira do Século XXI”, IPEA, Texto para Discussão 1452 .

AMSDEN, Alice. (2001), The Rise of "the Rest" - Challenges to the West from Late-industrializing Economies. Nova York, Oxford Press.

ANDERSON, Patrícia. (1999), “Câmaras setoriais: histórico e acordos firmados - 1991/95”, Texto para Discussão (Ipea), n. ${ }^{\circ} 667$.

ANFAVEA, (2014). Anuário da Indústria Automobilística Brasileira, 2014, disponível em http://www. anfavea.com.br/anuario.html

ANFAVEA, (2015). Anuário da Indústria Automobilística Brasileira, 2015, disponível em http://www. anfavea.com.br/anuario.html.

ARBIX, Glauco. (1996), Uma Aposta no Futuro. Os Primeiros Anos da Câmara Setorial da Indústria Automobilística. 1. ed. São Paulo: Scritta.

ARBIX, Glauco. (2007), Inovar ou inovar. A indústria brasileira entre o passado e o futuro. São Paulo: Editora Papagaio.

BEDÊ, Marco Aurélio. (1996), A indústria automobilística no Brasil nos anos 90: proteção efetiva, reestruturação e política industrial. 1996. Tese (Doutorado) - Faculdade de Economia e Administração da Universidade de São Paulo, São Paulo.

BOBBIO, Norberto. (1977) Dalla Strutura alia Funzione: nuovi studi di teoria dei diritto, 2" edição, Edizioni di Comunità, Milano.

CALANDRO, Maria Lucrécia. (2000), “A indústria automobilística brasileira: integração produtiva no Mercosul, regimes automotivos e perspectivas”. In: http://revistas.fee.tche.br/index.php/indicadores/article/viewFile/1661/2029, 2000.

CAMPANÁRIO, Milton de Abreu. (2004), Política Industrial, São Paulo: Plublifolha.

CHANG. Ha Joon. (2005) "Policy Space in Historical Perspective - with special reference to Trade and Industrial Policies1”, paper apresentado na Tufts University, disponível em http://www.ase.tufts. edu/gdae/about_us/leontief/Chang_remarks.pdf. Acesso 20.02.2017.

CIMOLI, Mario et al., "Institutions and policies shaping industrial development: an introductory note”. in: CIMOLI, Mario; DOSI, Giovanni; STIGLITZ, Joseph (Ed.). Industrial policy and development: the political economy of capabilities accumulation. New York: Oxford Press, 2009.

COMIN, Alexandre. (1998), De Volta para o Futuro: política e reestruturação industrial no setor automobilístico nos anos 1990, São Paulo: Anablume: Fapesp. 
De NEGRI, João (1999). O custo de bem-estar do regime automotivo brasileiro, in: Pesq. Plan. Econ., Rio de Janeiro, v. 29, n. 2.

EVANS, Peter. (1995), Embedded Autonomy: States and Industrial Transformation, Nova Jersey, Princeton Press.

GOVERNO FEDERAL. (2013), “Inovar Auto - 2013/2017”, apresentação do Ministério de Desenvolvimento, Indústria e Comércio, disponível em <www.desenvolvimento.gov.br/arquivos/ dwnl_1349358208.ppt>.

GOVERNO FEDERAL. (2013b). “Exposição de Motivos - MP 563, Texto disponível em <http://www. planalto.gov.br/ccivil_03/_Ato2011-2014/2012/Mpv/563.htm>.

KOHLI, Atul. (2004), State-Directed Development: Political Power and Industrialization in the Global Periphery, New York: Cambridge.

OGUS, Anthony (2004), Regulation: legal form and economic theory. Portalnd: Hart Publishing.

MESQUITA, Daniel Leite; BORGES, Alex Fernando; SANTOS, Antonio Carlos dos; SUGANO, Joel Yukata. (2013), “Aspectos Institucionais da Inovação: Uma Análise Acerca dos Regimes Automotivos Brasileiros de 1995 e 2012”, in: < http://www.altec2013.org/programme_pdf/671.pdf>.

PERES, Wilson e PRIMI, Annalisa. (2009), "Theory and Practice of Industrial Policy. Evidence from the Latin American Experience”. CEPAL - Serie Desarrollo productivo, n. ${ }^{\circ} 187$, pp. 5-48. disponível em <http://www.eclac.cl/publicaciones/xml/9/36449/LCL3013e.pdf>.

RODRIK, Dani. (2007), “Industrial policy for the Twenty-First Century”. In: RODRIK, Dani. (Ed.). One economics, many recipes: globalization, institutions and economic growth. New Jersey: Princeton University Press.

RODRIK, Dani. (2009), “Industrial policy: don't ask why, ask how”. Middle East development journal, v.1, n.1, Disponível em: <http://www.worldscientific.com/doi/abs/10.1142/S1793812009000024 ?journalCode $=$ medj $>$.

SALGADO, Lucia Helena. (1993). "Política da Concorrência e Estratégias Empresariais: Um Estudo da Indústria Automobilística”. Série Seminários No. 10/93, Brasília, Instituto de Pesquisa Econômica Aplicada (IPEA).

SCHAPIRO, Mario (2013). “Ativismo Estatal e Industrialismo Defensivo: Instrumentos e Capacidades na Política Industrial Brasileira”. Texto para Discussão (IPEA. Brasília), v. 1856.

SUZIGAN. Wilson \& VILLELA, Anibal. (1997), Industrial Policy in Brazil, Campinas: Unicamp.

TRUBEK, David; COUTINHO, Diogo; SCHAPIRO, Mario. (2012), "Toward a New Law and Development: New State Activism in Brazil and the Challenge for Legal Institutions”. in: Cisse, Muller, Thomas, Wang. (Org.). The World Bank Legal Review Volume 4: Legal Innovation and Empowerment for Development. 4ed.Washington: World Bank, 2012, v. 4.

WADE, Robert. (2004), Governing the Market - Economic Theory and the Role of Government in East Asian Industrialization. (2 ${ }^{\mathrm{a}}$. Ed.), New Jersey, Princeton Press.

WEBB, Kernaghan (1997). "Thumbs, Fingers, and Pushing on String: Legal Accountability in the Use of Federal Financial Incentives”, 31 Alta. Law Review, vol. 501. 